\title{
Los delirios de la razón: una crítica a las condiciones de posibilidad de las utopías
}

\author{
Wílmer Casasola Rivera \\ Escuela de Ciencias Sociales, Instituto Tecnológico de Costa Rica \\ Escuela de Filosofía, Universidad de Costa Rica
}

\begin{abstract}
Resumen
Este artículo aborda el tema de las condiciones de posibilidad del discurso utópico, su relación con las ideologías, así como con el presente y el futuro. También se refiere a algunas experiencias utópicas del pasado.
\end{abstract}

Palabras claves: utopía, sociedad, ideología, condiciones de posibilidad

\begin{abstract}
This article addresses the issue about the conditions of possibility for a utopian speech, its relationship with ideologies as well as the present and the future. It also refers to several utopian experiences in the past time.
\end{abstract}

Key words: utopia, society, ideology, conditions of possibility

\section{Introducción}

$\mathrm{E}$ 1 neologismo utopía nace con Tomás Moro. En su contexto etimológico, el término puede entenderse de dos maneras: literalmente hacia ningún lugar, o el mejor lugar posible, utopía y eutopía respectivamente.

Con la noción de utopía se hace referencia a un lugar perfecto, pero inexistente. Se trata del mejor lugar que está en ninguna parte, el mejor lugar inexistente. La estructura social de las utopías permite la absoluta felicidad de sus habitantes. Esa es la razón por la cual el adjetivo utópico indica la imposibilidad de realización y el sustantivo utopista alude a toda persona idílica, con una imaginación flotante que le permite crear sociedades perfectas. De esta suerte, la utopía tropieza con una paradoja: "La utopía es la sociedad o comunidad sin lugar y la sociedad o comunidad mejor" (León del Río, 2006). Para Servier, los utopistas son "todos aquellos que han soñado con reformar la sociedad" (1987, p.104), pero lo único que logran es trazar el mapa imaginativo de sus creaciones idílicas. 
La utopía es una creación literaria, un discurso que juega conjuntamente con la fantasía y la erudición filosófica. A partir de este doble juego, busca anclar en la mente de los argonautas lectores, una representación más allá de la realidad vivida en el presente por medio del acto de la escritura. Es, como indica Marin, "un texto cuya realidad no está en ninguna parte[...], el producto de su propio juego en el espacio plural que construye”. (1976, p.76)

Dentro de este espacio imaginativo, las utopías describen un mundo feliz. Son originalmente lugares existentes pero desconocidos por el común de los mortales. Pero también la utopía evoca tiempos pasados, o bien tiempos futuros. En ambos casos se da una embriaguez de nostalgia por un mundo perfecto que no encontrará más allá de la escritura que le da vida. Como nostalgia por el pasado, las utopías empezaron siendo eucronías. De acuerdo con el discurso de religiones y cosmogonías, hubo una edad de oro en que la humanidad vivía en el principio de los tiempos en un estado de completa felicidad, antes de que empezara paulatinamente a introducirse el mal en la Tierra, momento en el que se pasa a la edad de hierro. Por su lado, la nostalgia por el futuro surge a raíz de la insatisfacción por el presente. Se inaugura entonces la ciencia ficción, la cual no tratará ya de construir sociedades humanísticas, sino tecnológicas. La ciencia ficción se construye de acuerdo con el conocimiento vigente, para recrear una sociedad científica y tecnológicamente avanzada, superior. El mito, tanto hacia el pasado como hacia el futuro, es el producto de una limitación de nuestra capacidad epistémica por explicar la realidad del presente y del pasado.

La realidad social del presente es lo que motiva al escritor a cabalgar en las nubes de su imaginación recreando sociedades perfectas. Y qué mejor lugar que el futuro, condición de posibilidad de todo acto imaginativo. Cualquier escenario puede ser objetivo de una utopía; lo que importa es apuntar hacia el futuro y afirmar que "en algún lugar del mundo, en algún momento del porvenir o más allá de la muerte debe existir la posibilidad de vivir felizmente”. (Las utopías, p.25)

La utopía describe una realidad imaginativa que pretende instaurarse en la práctica cotidiana. La utopía es ingenuamente optimista; sin embargo, opera como una forma de pensamiento lúdico que critica las bases de una sociedad injusta por infinidad de motivos y es la desigualdad económica un punto fundamental. En este proceso imaginativo, lúdico, el narrador utópico critica la estructura social de su tiempo y edifica toda una arquitectura fantástica para poner en marcha una sociedad racionalmente perfecta. El narrador utópico esquematiza implícitamente las deficiencias de la sociedad y transforma su discurso en una herramienta de análisis. "Así, se convierte en un crítico y su relato en una reflexión acerca de la sociedad, el hombre, sus creaciones, el poder y el sentido de la historia" (León del Río, 2006). Esta reflexión, que vuela en las nubes de la razón, de alguna forma anhela la realización de un gobierno perfecto. Es decir, las utopías, mediante el proceso narrativo, persiguen, en alguna medida, establecer las condiciones de posibilidad de su universo lúdico. Lo que cabe analizar, entonces, son las condiciones de posibilidad o de realización de un planteamiento utópico, al punto de examinar la separación o unión del reino de la fantasía y el reino de la realidad. 


\section{El despertar de la utopía}

Realizar algunas observaciones insidiosas al ideal de las utopías, lejos de restarle méritos, puede contribuir, aunque sea lábilmente, a comprender más sus alcances y limitaciones en la dinámica del imaginario social.

La noción que más se aproxima a la de ideal ético es quizás la de utopía. Aunque, claro está, esta sinonimia es bastante laxa y se aproxima más a un lenguaje popular. El término ideal pertenece más a los contextos gnoseológicos y ontológicos, en tanto que el término utopía se emplea más en el mundo literario e ideológico.

Cuando Tomás Moro introduce el término utopía, no solo crea una palabra, sino que inaugura un género literario-filosófico que se caracterizará por la construcción imaginaria de sociedades ideales donde todo marcha de acuerdo con una perfecta organización, al procurar una vida feliz, justa y equitativa. En una palabra, el tema común de toda utopía es la presentación de una sociedad perfecta. En consecuencia, ideal y utopía se corresponden en la medida en que apuntan hacia el futuro, hacia un momento de perfección. Tanto el ideal como la utopía comparten en algún grado la imperfectibilidad de la realidad humana presente y se orientan hacia una propuesta de perfectibilidad de la conducta moral.

Según Miguel Ángel Granada, abundantes eran las fuentes de las que Moro se nutrió, como lo son en efecto "la apertura de un mundo conocido gracias a los descubrimientos geográficos, que venían a añadir un «orbe nuevo» al viejo con todo tipo de noticias sorprendentes y maravillosas" (1988, p.558), así como la literatura griega sobre viajes y formas de gobernar.

En nombre de las utopías pueden crearse reinos fantásticos anclados aquí en la Tierra. Como ejercicio idílico literario es un buen recurso, no así si se pretende una propuesta de cambio social seria, estratégicamente planificada. El género se legitima al punto de que la imaginación salta azorada al creer que la formulación de una utopía es sinónimo de su realización, o bien, la vía de una posibilidad de vida mejor. ${ }^{1}$

Adolfo Sánchez sostiene que del diseño platónico están ausentes dos ingredientes propios de la utopía moderna: "la imagen del futuro" y "la posibilidad de su realización en el mundo empírico" (2000, p.292). En cuanto a la imagen del futuro, el Estado ideal, se halla fuera del tiempo. Las condiciones de posibilidad apuntan simple y llanamente a la posibilidad de realización en el mundo empírico, para lo cual la utopía debe describir una cierta imagen del futuro. La proyección futura queda como garante de la posibilidad de realización. Esto quiere decir que la utopía inscrita en un espacio y tiempo determinados aniquilaría su posibilidad de realización, porque siempre está lo futuro como su posibilidad y perfectibilidad. Lo futuro es la posibilidad de perfección, mientras que lo presente carece de ese grado de perfección del ideal utópico.

Toda utopía es la construcción ideal de una sociedad perfecta. Esta perfección no puede anclarse en la realidad inmediata del presente, por lo que el futuro se presenta como la posibilidad de su realización. Pero el futuro es también un tiempo ideal mediatizado por algo tan simple como las mismas desavenencias 
naturales y, por lo tanto, propenso a sufrir los cataclismos que la misma naturaleza provoca, de donde se sigue que el futuro, como medio para realizar la utopía, es un argumento inconsistente. Por otra parte, apelar al futuro como tiempo de realización no es en sí mismo nada, debido a cuestiones de carácter natural. Sin embargo, otro punto por considerar con respecto a la apelación al futuro como garante de realización utópica, corresponde a los aspectos sociales y sus continuos cambios. En efecto, la sociedad está siempre en un continuo cambio, por lo que las proyecciones a futuro de una cierta sociedad posiblemente no encajen como modelo de convivencia ni como proyecto de vida, dados los proyectos puramente existenciales. Pero, si tomamos en cuenta los factores económicos, políticos y hasta ideológicos, las condiciones de posibilidad utópicas cambian aún más radicalmente, porque la experiencia va construyendo cierto imaginario moral y social. Lo que hoy se proyecta como idealmente perfecto, mañana puede no serlo en absoluto. Lo mismo dígase en el plano moral y ético: lo idealmente bueno y correcto hoy, puede ser absolutamente rechazado al caminar de unas cuantas décadas.

Al igual que Platón en la República, o Aristóteles en la Política, Tomás Moro también busca responder a los problemas que enfrenta la realidad social de su tiempo y, en concreto, a la realidad social de Inglaterra; trata con su obra de dar respuesta a "los problemas planteados por la miseria del país bajo el reinado de Enrique VIII" (Servier, 1987, p.41) y, en consecuencia, a "la desesperación de los humildes de toda Europa, y tal vez también a las aspiraciones políticas de una burguesía demasiado alimentada por la República.” (Servier, 1987, p.39). Todo ello, desde luego, en el marco de una fantasía social, más cerca de Platón que de Aristóteles.

La creación de una imagen del futuro, que sería una condición necesaria para su posibilidad de realización, es también idealmente estática. Apelar al futuro no le confiere a la utopía esa condición de plasticidad y de posibilidad realizable. El futuro es una construcción ideal, al que se apela con frecuencia como coartada para evadir la responsabilidad del presente. Con el futuro, la utopía "se convierte en ciencia-ficción, negando las miserias del presente para buscar refugio en futuros que promete encantadores" (Servier, 1987, p.106).

En el ámbito político-social, se llega a creer que la "anticipación de una vida justa" y digna, aunque "todavía no es", "puede ser en el futuro" (Sánchez, 2000, p.292). Adolfo Sánchez, siguiendo de cerca la idea de Neüses de dos modelos de utopía (horizontal y vertical), cree que la idea de esta vida justa y digna puede apartarse de la verticalidad utópica platónica y aproximarse a la horizontalidad, propia de la modernidad hasta nuestros días. Este modelo horizontal de utopías sería el llamado a presentar la efectividad de las condiciones de posibilidad empírica.

La crítica que hace Sánchez, tanto de la utopía platónica como de la cristiana, es su falta de "voluntad de realización”. Es decir, faltan, tanto "en la versión cristiana medieval, como en la platónica, la dimensión humana de lo posible y lo realizable, característica de la utopía moderna desde el Renacimiento." (Sánchez, 2000, p.293). Se apela entonces al futuro como condición de posibilidad. 
Sánchez expresa poéticamente lo siguiente: "La utopía mira con un ojo al futuro y con otro, al presente" (2000, p. 293). El problema de esta afirmación es que uno de esos ojos percibe la realidad obnubiladamente y, en consecuencia, o no mira bien el presente e interpreta mal el camino hacia el futuro, o mira idílicamente el futuro y desvirtúa la riqueza de la realidad presente.

Es preciso tener en consideración que toda utopía es la manifestación de una ideología que busca determinar la vida social en su totalidad y en este sentido - y dependiendo de cuál sea la vertiente de la que se nutre-, el ideólogo siempre verá en la ideología que sustenta la única transformación posible de la realidad por medio de esas ideas y, por lo tanto, es capaz de ver solo las virtudes de su doctrina, pero de modo alguno las virtudes fácticas del pensamiento divergente.

En las utopías modernas de los siglos XVI a XVIII, se realiza una crítica de las condiciones sociales de sus habitantes. La visión de estos pensadores utópicos sobre esta situación permite lanzar críticas no solo al presente, sino imaginar las condiciones futuras de una mejor vida social:

A partir de esta visión del presente, llevan a cabo una dura crítica de lo existente y proponen modelos de alternativas sociales, dotadas de instituciones, descritas prolijamente, que permitan eliminar los males criticados. Así, pues, las utopías modernas no sólo anclan en lo real y critican el presente, sino que se internan imaginativamente en el futuro y exploran lo posible. Anticipan con ello una realidad que no es todavía, pero que puede y debe ser". (Sánchez, 2000, p.294)

Sánchez cree que con la formulación de "un modelo de sociedad" justo se sigue necesariamente "una voluntad de realización de lo utópico" (2000, p.294). El problema es que la formulación de estas sociedades construidas imaginativamente deja por fuera muchos aspectos de la realidad humana. De acuerdo con esto, no sería ya la experiencia la que configura el devenir de la moral, sino el modelo teórico el que determina lo que sería la moralidad social. La imaginación utópica aniquila la posibilidad imaginativa del resto de integrantes de esta sociedad, a tal punto que es el demiurgo creador de estos modelos justos quien determina a priori las condiciones físicas y psicológicas en las que sus miembros se desenvolverán. En efecto, dado que los planos de estas sociedades justas son trazados por su creador desde el principio hasta el fin, él establece los parámetros de libertad física en la que sus habitantes deben movilizarse, de modo que para salir de sus fronteras, hay que contar con la venia de su o sus gobernantes. Y si por alguna natural razón deciden fugarse de ese paraíso terrestre de felicidad, son castigados por cometer un delito ignominioso. Considérese la siguiente opinión de Moro: "Si alguien sale espontáneamente fuera de los límites de sus territorio y es cogido sin poder presentar un permiso del príncipe, comete un delito ignominioso; aprésanlo como fugitivo y es castigado severamente. Si reincide, es reducido a la esclavitud" (2006, p.93). ${ }^{2}$ Pero lo cierto es que esta es la realidad de los ideales construidos a partir de una racionalidad pura, que se quieren modelos 
justos de sociedad. El determinismo ideológico marchita la posibilidad de formular proyectos de vida de manera autónoma y, en su lugar, determina lo que debe ser la libertad, tanto física como sicológica.

Unos quisieron, dado el estatus con que ha contado la ciencia desde que inicia su faena, ataviar su discurso bajo el abrigo de este saber y, de esta manera, su discurso deja de ser utópico para convertirse en un discurso científico. Lo que hace científico este discurso es, en apariencia, el conocimiento y crítica de la realidad presente, la cual, mediante un plan de acción, ofrece las condiciones en las cuales esta realidad se puede transformar para bien de la humanidad. Un marxista como Adolfo Sánchez reconoce que hay "una utopía en Marx, y la hay como proyecto de emancipación o de sociedad futura; es decir, como alternativa social al sistema de dominación y explotación capitalista" (2000, p.296). Esta sociedad imaginaria y deseable para algunos conlleva, sin embargo, una serie de abstracciones que la alejan de la realidad práctica cotidiana de la vida humana y sus condiciones de posibilidad parecen más la manifestación de una acción violenta que racional y democrática. A tal punto es una manifestación violenta que la libertad y felicidad humana están mediadas por lo que sus creadores consideran lo que es y no es felicidad y libertad.

Sin embargo, siempre existe la tentación de encontrar un argumento para sostener la posibilidad de estas creaciones imaginativas, pese a que la persona humana, a la que va dirigida la potencial posibilidad de realización de felicidad, es la primera que duda en lograrla. Brightman había dicho que "la apelación a lo puramente emotivo es irrelevante en lógica, sea quien fuere quien la haga. Sin duda la emoción es de gran importancia en la vida; pero no por eso sirve para demostrar la veracidad de los principios, ni para dirigir la razón" (1945, p.1234). Si lo emotivo es irrelevante en lógica, con mucha más razón lo será en ciencia, en física, en estadística y economía. Hay en las ideologías un alto grado de estimulantes emocionales que en lugar de presentar las condiciones de posibilidad de una transformación social en el presente y bregar con las limitaciones existentes, con los sistemas económicos existentes, con la situación geopolítica existente, con las ideologías opuestas existentes, lanzan sus proyectos hacia el futuro esperando que, allende lugares lejanos, aparezcan los sujetos históricos que llevarán a cabo esas algarabías literarias. De esta manera, bajo los encantos de estos galimatías discursivos, muchos se creen actores sociales, comprometidos con la desigualdad social y responsabilizan a otras personas por permitir que muera la utopía. Entonces, estos actores sociales intelectuales se encargan de presentar las condiciones de posibilidad utópica en el presente para que sean realizadas en el futuro, pero siempre como una construcción racional alejada de la posibilidad de la vida empírica en sociedad. Pues, así como "el presente es el tiempo de lo real, el futuro es el tiempo de la utopía" (Sánchez, 2000, p.298). Este "rasgo es una exigencia literaria para hacer posible y plausible la existencia real de la sociedad perfecta en el momento contemporáneo" (Granada, 1988, p.561). Pero el futuro, si nos atenemos a que es el tiempo que se conoce por el presente, puede nunca llegar, pues cada vez que estemos en el presente, el futuro estará ausente y así caemos en la comedia zenoniana; en consecuencia, nunca llegaremos a ese 
futuro que permitirá la realización de esta sociedad feliz. Si de alguna manera se considera que la moral presente es imperfecta, se estaría juzgando entonces la perfección moral del futuro a partir de la imperfección moral del presente, lo cual no solo resulta aporético, sino absurdo, pues ¿cómo desde la imperfección presente se puede construir la perfección futura? El asunto es que nunca se llega a esa perfección de la moralidad y la convivencia social.

La utopía existe en otro tiempo, en un tiempo o mundo ideal realizable como posibilidad en el futuro. En la proyección de una vida mejor en el futuro, la utopía parte de una crítica de las condiciones sociales del presente. En este sentido, se cree que como se critica la realidad existente, la utopía es la "anticipación de una vida mejor" (Sánchez, 2000, p.298). Dado que existe una incongruencia o distancia con la realidad que se critica en el presente, esta última nunca se puede superar totalmente, pues "lo ideal no se agota en lo real" (Sánchez, 2000, p.299). Esto quiere decir que la utopía no se realiza en la realidad presente, sino en la realidad del futuro, el cual, como vimos, es una construcción ideal y, por lo tanto, siempre va a estar alejada. La utopía sería entonces irreductible a la realidad. "Su reducción significaría irrevocablemente el fin de la utopía", o bien, "una utopía real o realizable no sería ya tal" (Sánchez, 2000, pp.299, 301). Esta idea la sostiene Pescador, quien cree que los "objetos ideales no sólo son irreales sino que también son irrealizables", con lo que los objetos ideales podrían ser "conocidos y comprendidos, pero nunca realizados" (1966, p.53). Lo que subyace aquí es la noción de que el ideal es más perfecto que la realidad, en la misma proporción que la utopía. En este sentido, la utopía proyectada hacia futuro sería más perfecta que la realidad presente. No cabe más que perfección en su planteamiento, porque de no serlo, ¿qué sentido tendría crear sociedades perfectas? Resulta verdaderamente absurdo crear utopías con miras a su realización, si una utopía realizada sería el fin de esta. Esto, en sentido estricto, podría perfectamente interpretarse como que las utopías, como género literario, sirven para evadir la realidad presente, pero como un entretenimiento eminentemente lúdico, nunca como una alternativa real, con un plan estratégico para la acción o puesta en marcha.

Como elucubraciones racionales, estas utopías de alguna forma dibujan cierto nuevo humanismo. Como tal, el tipo de ser humano ahí elaborado, corresponde a cierto modelo ideológico. Ciertamente, las utopías responden a los intereses de ciertas élites sociales en cambiar la realidad existente, como lo ha expresado el mismo Adolfo Sánchez: "Las utopías responden a aspiraciones y deseos de clases o grupos sociales que se muestran inconformes o críticos con respecto a determinada realidad social" (2000, p.300). Detrás de de toda utopía hay una ideología que la sustenta. Esto también lo sostiene Adolfo Sánchez cuando escribe que "toda utopía supone o entraña una ideología, aunque no toda ideología motiva o genera una utopía” (2000, p.300). Sin embargo, es atrevido decir que una utopía responde a los intereses de una sociedad. Hay que tener siempre presente que todo ideal que se crea, toda utopía o ideología, no es sino la percepción que un determinado autor, o comunidad, tiene de la sociedad. Que la argumentación de sus ideas arrastre, cual aluvión impetuoso, a una serie de acólitos que creen en 
su proyecto, no que quiere decir que ese sea el interés general de toda una colectividad humana. No hay que olvidar, tal y como lo ha señalado Servier, que los utopistas, es decir, aquellos que han soñado con reformar una sociedad, expresan el pensamiento de un grupo y de una clase social determinada (1987, p.104). La crisis que ellos dicen evidenciar es la que perciben de acuerdo con la élite que los sustenta y la que quieren sustentar según intereses evidentemente personales.

Las utopías son ucronías futuras y esta es su piedra angular, el portillo hacia su propio cadalso. ¿Por qué? Por la sencilla razón de que la experiencia humana cambia. La persona cambia su forma de percibir la belleza, la justicia, la igualdad; cambia la forma de esparcir su ocio, de entretenerse; cambia su gastronomía; en una palabra, cambia su estética de la vida. La utopía, o las utopías, obedece a un tiempo y espacio histórico determinados. La sociedad de una época está inscrita en una sensibilidad condicionada por los acontecimientos del vivo presente, por lo que esa percepción de la vida cotidiana no se puede extrapolar a tiempos futuros, pues hacerlo representaría un disparate anacrónico. Peor aún si tomamos en cuenta que el literato o escritor responde a la realidad que percibe desde el lugar o estatus que sustenta, por lo que esta percepción no puede erigirse en el interés de toda una colectividad humana. Los sueños del presente no tienen por qué ser la realidad del futuro, a no ser que se trate de la proyección onírica del propio individuo. Un Estado, un país, una nación solo tienen que ofrecer las condiciones de posibilidad para que este sujeto sueñe como quiera soñar, pero en modo alguno este Estado, este país o esta nación deben determinar ideológicamente los intereses de unos pocos en nombre de toda una colectividad humana. Estas son utopías e ideologías coercitivas.

\section{Las utopías coercitivas}

Las utopías, al igual que los ideales, cuando son sustentadas por ideologías coercitivas atentan contra la libertad individual. En este sentido, la libertad que se cree tener, no es tal, pues hasta los parámetros físicos son claramente delimitados, por lo que la libertad es una mera ficción. Se trata de sociedades cerradas en las que las personas deben adaptarse al modelo concebido por el utópico. En su afán de garantizar la felicidad del ser humano, le opaca el candil de la felicidad misma. Si cabe cuestionar las condiciones de posibilidad de la utopía misma, cabe cuestionar las propias condiciones de posibilidad de la felicidad de los miembros de esa colectividad aparentemente feliz.

De acuerdo con lo anterior se puede plantear, a modo hipotético, que las utopías los conducen a un determinismo ideológico que suprime la capacidad de imaginar y crear otras formas de vida, pues las utopías determinan la justicia, la libertad, la moral, el entretenimiento, el comportamiento social y hasta el ocio, a partir del sueño de reformar de manera perfecta a una sociedad. Específicamente una utopía, al igual que una ideología, no se critica a sí misma. En consecuencia, se trata de un sistema cerrado de ideas, y en esta medida, las condiciones de posibilidad como modelo de conducta y acción humana empiezan a resquebrajarse desde su interior. 
Servier sostiene que la ciudad regida por leyes justas y en general por un modelo de perfección racional, "es en realidad un molde rígido, restrictivo, del que sólo pueden resultar personalidades adaptadas conforme a la utopía” (1987, p.109). Son efectivamente los utopianos los que disfrutarían de esta sociedad perfecta. Lo mismo puede decirse de los comunistas, de los socialistas, de la ultraderecha o de cualquier autoritarismo o totalitarismo: solo ellos encuentran perfecto el sistema en el que viven o quieren sustentar. ¿Y compartirán su fervor religioso el resto de los mortales? Evidentemente no. Por eso es que se habla del carácter coercitivo de las utopías, hasta el punto de que las mismas leyes no están enfocadas en procurarles o garantizarles felicidad a sus propios integrantes, sino que como señala Jean Servier, lo que prevalece es "el carácter coercitivo de las leyes justas, leyes que se imponen al individuo en nombre del mito de la organización del universo, en nombre de la armonía cósmica" (1987, p.111). O bien, para no parecer tan exagerados como Servier, hablemos mejor del mito de la organización y armonía del Estado, donde unos cuantos ilustrados conocen misteriosamente esta armonía y la comunican a los demás de forma coercitiva. Esta coerción está íntimamente ligada a la universalidad de unos principios y fundamentos morales válidos para todos. Según Bauman, la universalidad para los legisladores sería la regla de un grupo de leyes que prevalecerían en un determinado territorio sobre el cual se extiende su soberanía, mientras que los fundamentos consistirían en los poderes coercitivos del Estado, que hacen posible la obediencia a las reglas. Para los filósofos, la universalidad tendría la característica de prescripciones éticas que obligan a cada ser humano a reconocerla como válida y aceptarla como obligatoria, mientras que una regla bien fundamentada sería aquella que ofrece una respuesta convincente a la pregunta sobre su obediencia (2005, p.15). Y aquí volvemos al tema de los primeros principios y el supuesto desarrollo de una logicidad superior: los que no estén a favor de estas causas avocadas a la supuesta dignidad humana es porque aún no han llegado a una etapa de razón ni de discernimiento; los que no logran ver el fin benevolente de esa causa social, aún no comprenden la realidad social misma.

Recordemos las palabras de José Ingenieros en relación con la genealogía ontológica del ideal. "La imaginación, partiendo de la experiencia, anticipa juicios acerca de futuros perfeccionamientos: los ideales, entre todas las creencias, representan el resultado más alto de la función de pensar" (2004, pp.17-18). Sánchez, con gran similitud, sostiene que la utopía se halla vinculada con la realidad y que no solo "ésta genera su idea o imagen del futuro", sino que además la utopía "incide en la realidad con sus efectos reales". En consecuencia, "la utopía no sólo tiene una existencia ideal, sino también real, efectiva, por su capacidad de inspirar el comportamiento práctico de individuos o grupos sociales, produciendo efectos reales en la realidad presente" (Sánchez, 2000, p.299). El momento de lucidez le llega a Sánchez cuando concluye que "la utopía no es el reino de lo absolutamente imposible, ni tampoco de lo posible sin más, sino de lo posible en determinadas circunstancias y condiciones" (2000, p.301). Esta afirmación está más en consonancia con una causalidad condicionante y, en consecuencia, 
con circunstancias que favorecen o no las posibilidades de realización de ciertos ideales llamados éticos.

La pérdida de la vigencia de las utopías se da por la extensión de las ideologías, pero a su vez, por el escepticismo hacia las utopías mismas. Pero estas son ideologías. El escepticismo se deriva del desencanto de los efectos perversos que tuvo el llamado socialismo real. La humanidad ha aprendido que esos cósmicos proyectos humanitarios solo son la excusa de la búsqueda incansable tanto del poder como del control y que el pueblo, el que ayuda a levantar los cimientos de este poder, es el primero en sufrir las consecuencias represivas de unas sociedades coercitivamente totalitarias. Sociedades que nacieron en sus esquemas imaginarios cerradas, se desarrollaron represivamente cerradas y mueren -o morirían- asfixiadas por esta estructura política cerrada. La pérdida de vigencia y credibilidad de las utopías ha sido, en parte, producto de las críticas conservadoras que ven en el realismo político el tratamiento objetivo de los problemas de la realidad social. Ante estas críticas, la reacción de los utópicos es tratar de salvar la vigencia de las utopías cuestionando las condiciones en que una vida actual digna es posible con el solo concurso del cruel y devastador monstruo capitalista, sin recurrir al sueño y esperanza de un mundo mejor en el futuro. Y como estas críticas antiutópicas se concentran en señalar el fin de las utopías, entonces los defensores utopistas lanzan esta pregunta: “¿cuáles serían las condiciones de posibilidad de su fin?” (Sánchez, 2000, p.306). Es decir, ante la irrealización de una utopía, se cuestionan las condiciones en las que el fin de una utopía es posible. No importa tanto si las utopías son irrealizables, lo verdaderamente importante es cuáles son las razones - las condiciones_ por las que tienen que llegar a su fin.

Entonces se dice que si no puede haber la crítica y el sueño de una mejor vida, es decir, "si el fin de la utopía se vuelve imposible, un mundo sin utopías sería una utopía más" (Sánchez, 2000, p.307); o bien, "la crítica anti-utópica, puede albergar también en sí misma elementos utópicos” (Neusüss, 1971, p.27). ¿Por qué un mundo sin utopías es una utopía más? La utopía es la realidad onírica del presente y la esperanza de realización futura. No soñar con sociedades perfectas, sino vivir con la sociedad que se tiene, no tiene por qué ser una utopía, ni ser tampoco un conformismo. Por otro lado, en relación con estos proyectos utópicos, ¿la utopía de quién o de quiénes? Si bien es cierto que en el realismo cotidiano se debe bregar día tras día por la supervivencia individual, no quiere decir que la creación de estas sociedades imaginarias sea la panacea para la solución de los problemas de miseria individual humana. En la formulación de estos megaproyectos existenciales se descuida por completo la realidad individual concreta. En nombre del realismo político, de una razón de Estado, se descuida por completo el realismo cotidiano, la razón individual.

El ortodoxo conservador Neusüss ${ }^{3}$ cree que la antiutopía es la manifestación de la forma del pensamiento liberal; o bien, tal y como él lo expresa, "los compromisos utópicos del liberalismo". Según Neusüss, la diferencia entre el pensamiento utópico y estas formas liberales de pensar "estriba en su grado de radicalización" (1971, p.27). Con esto, no hacemos sino volver a aquella metáfora de la paja y la viga. Lo que ignora Neusüss, así como cualquier intelectual en- 
cajonado en estos megaproyectos sociales, es el alto grado de radicalización de un proyecto de esta magnitud. La interrogante de Adolfo Sánchez sobre cuáles serían las condiciones de posibilidad del fin de las utopías se puede cuestionar desde la pregunta opuesta, a saber, ¿cuáles serían las condiciones de posibilidad para que no llegue a su fin? Entonces ya no es necesario hablar de cuáles serían las condiciones de su fin, sino más bien, el análisis de por qué las condiciones sociales permiten la imposibilidad de la realización de la utopía. Las condiciones de imposibilidad de estas utopías son su radicalidad imaginativa sin un referente empírico que las sustente.

Los utopistas ortodoxos y conservadores reprochan que siempre hay unas objeciones tipificadas hacia las utopías que van desde su posibilidad de realización, pasando por su totalitarismo, hasta objetar su escatología ${ }^{4}$. Esta crítica hacia las utopías proviene de los conservadores y liberales. Dentro de estas críticas, según Neusüss, la "más primaria y conservadora, se basa casi siempre en el criterio de la posibilidad de su realización" (1971, p.28); pero, ¿qué otra crítica primaria se le podría formular? El mismo género fantástico ha dado lugar al cuestionamiento sobre las posibilidades de realización de las utopías. Este perfeccionamiento y funcionamiento detallado de una sociedad futura ha dado lugar para cuestionar, en toda época de la historia hasta nuestros días, las condiciones de posibilidad de estos ideales morales englobados bajo el concepto de utopía. Andreas Voigt considera que las utopías son "representaciones ideales de otros mundos, cuya existencia o posibilidad no se puede determinar científicamente, sino que en ellas sólo se puede creer" ${ }^{5}$

Si bien es cierto, no son lo mismo, ciertas utopías están asociadas a proyectos socialistas. Cuando se apela a la carencia de criterios científicos para determinar la validez de su realización, puede darse una variedad de respuestas, tanto para justificar los motivos por los que la utopía no se puede llevar a la práctica, como para justificar los motivos de su fracaso. Posiblemente, esta apelación a la carencia de criterios científicos llevó a un grupo de autores soviéticos, en el último estertor agónico del imperio comunista, a realizar propagandas según las cuales los científicos estaban abordando el nuevo modelo de desarrollo de la sociedad soviética. Muchos expertos ${ }^{6}$ se refirieron al tema del socialismo tratando de mostrar las virtudes de este sistema, tal y como lo demuestran las palabras del economista Otto Lacis: "Nosotros respaldamos el socialismo no por razones religiosas, sino porque demuestra con toda evidencia que la gran producción social es, en definitiva, más eficiente que cualquier otra" (DUR, 1990, p.8). Sin embargo, hubo quienes desafiaron esta postura dogmática y criticaron el sistema socialista. Entre ellos el filósofo Vladislav Kelle, quien señalaba que había que dejar de forzar la historia y por ello mismo, dejar de "adaptar la historia al ideal del socialismo" (DUR, 1990, p.11). Aún más radical es la crítica que hace el economista Evgueni Ambartsumov, quien señala que en Occidente la gente no se pone a discutir cómo debe ser la sociedad capitalista, o qué es el capitalismo, mientras que ellos, los socialistas, siempre están construyendo teorías y quejándose de que el mal principal está en la ausencia de una buena teoría. La conclusión de Ambartsumov es la siguiente: "Tenemos que irnos 
deshaciendo de nuestro idealismo, del mesianismo y, claro está, de la sociedad totalitaria [y] tener bien claro el hecho de que el camino más corto, por el que queríamos construir la sociedad justa, no conduce a ningún lugar" (DUR, 1990, p.14). Precisamente esta es la noción elemental de utopía: hacia ningún lugar.

\section{Notas}

1. Pese a esta afirmación, la historia de las utopías registra algunas llevadas a la práctica. Se trata, sin embargo, más de una proyección comunitaria de unos cuantos que de un proyecto teórico racionalmente elaborado. Presento algunas utopías - más bien proyectos comunitarios-, sin que estas agoten la existencia de otras proyecciones utópicas: George Rapp (1757-1847): Harmony Society. Rapp era un pastor luterano separado de la iglesia y estableció su comunidad en Norteamérica en 1804, en Butler County, Pennsylvania. Pero posteriormente (1814), trasladó su comunidad a Wabash River, Indiana. Su ideal era la espera de la segunda venida de Cristo. Frances Wright (1795-1852): Nashoba, fundada en 1826 cerca de Memphis, Tennessee, una comunidad de negros y blancos con el ideal de encarar el problema de la esclavitud. Pese a ello, eran los blancos quienes administraban los trabajos de los negros. George Ripley (1802-1880): Brook Farm, fundada en Massachussets, cuyo ideal consistía en que el trabajo y la maquinaria social necesaria para la vida fuera reducida al mínimo y que en su lugar se cultivara el desarrollo espiritual y mental. Charles Fourier (1772-1837), cuyo ideal consistía en la supresión de las revoluciones. Cabe recordar que la familia de Fourier perdió todo su capital durante la Revolución Francesa. Josiah Warren (1799-1874): Modern Times. Establecida en un primer momento en Ohio, en 1847, y posteriormente en Long Island, en 1851, perseguía el ideal de la soberanía individual y el comercio equitativo. John Humphrey Noyes (1811-1886), en 1835 fundó la Adult Bible School, una forma de religión que creía en el perfeccionismo, cuyo ideal era la terminación inmediata del pecado por medio de la vida comunal. También una serie de colectividades anarquistas que no considero aquí. (Véase Wallechinsky,1977, 275 ss).

2. Cualquier similitud con sifograntes e islas paradisíacas de nuestro siglo XXI es pura coincidencia.

3. Nada más ortodoxo y conservador que un grupo de intelectuales que pretenden fijar de una vez y para siempre la experiencia humana en unos parámetros físicos y psicológicos en nombre de una supuesta sociedad perfecta. Aquí se detiene todo progreso en nombre de una sociedad perfecta que se fija en el presente como la más perfecta de todas, sin tomar en cuenta el devenir de la experiencia misma.

4. Cabe señalar que por escatología se entiende el conjunto de creencias o doctrinas de ultratumba, o bien, el tratado de cosas excrementicias.

5. Cit.pos., Neusüss, A. (1971, p.33).

6. A comienzos de 1990 hubo una mesa redonda, en la redacción de Pravda, donde se presentaron y discutieron los problemas del ideal socialista y del socialismo contemporáneo, así como las vías de la reforma de la sociedad soviética. La mesa redonda está contenida en un documento intitulado De la utopía a la realidad. En adelante emplearé las siglas DUR para referirme a este documento. 


\section{Bibliografía}

Bauman, Z. (2005). Ética posmoderna. (B. R. de la Concha, tr.). México: Siglo XXI Editores.

Berberi, M.L. (1975). A través de las utopías. (E. Leite, tr.). Buenos Aires: Proyección.

Brightman, E. (1945). Una filosofía de los ideales. México: Centro de Estudios Filosóficos de la Facultad de Filosofía y Letras.

De la utopía a la realidad (1990). Moscú: Editorial de la Agencia de Prensa Nóvosti.

Fernández de la Mora, G. (1986). El crepúsculo de las ideologías. Madrid: Espasa-Calpe.

Granada, M. Á. (1988). La filosofía política en el Renacimiento: Maquiavelo y las utopías. En V. Camps. Historia de la ética. De los griegos al Renacimiento. Barcelona: Crítica

Ingenieros, J. (2004). El hombre mediocre. Buenos Aires: Longseller.

Kolakowski, L. (1971). Crítica de la utopía. México: UNAM.

Las utopías (1973). Barcelona: Salvat Editores.

León del Río, Y. (2006). Historia y lógica del concepto de utopía. Utopía y Praxis Latinoamericana, 11 (34). Versión digital http://www.scielo.org

Manuel, F. E., ed. (1982). Utopías y pensamiento utópico. Madrid: Espasa-Calpe. Marin, L. (1976). Utópicas: juegos de espacios. Madrid: Siglo Veintiuno Editores. Molnar, T. (1970). El utopismo: la herejía perenne. Buenos Aires: EUDEBA.

Moro, T. (2006). Utopía. (R. Esquerra, tr.) Madrid: Mestas

Morton, A.L. (1952). Las utopias socialistas. (R. de la Ingesia, tr.). Barcelona: Ediciones Martínez Roca.

Moulian, T. (2001). Socialismo del siglo XXI. La quinta vía. Santiago de Chile: LOM.

Neusüss, A. (1971). Dificultades de una sociología del pensamiento utópico. En A. Neusüss, Utopía (M. Nola, tr.). Barcelona: Barral Editores.

Pescador, A. (1966). Ontología. Buenos Aires: Losada.

Sánchez Vázquez, A. (2000). Entre la realidad y la utopía: ensayos sobre política, moral y socialismo. México: UNAM.

Servier, J. (1987). La utopía. (Ernestina Carlota Zenzes, tr.). México: Fondo de Cultura Económica.

Utopía (M. Nola, tr). Barcelona: Barral Editores.

Wallechinsky, D. (1977). Almanaque de lo insólito. Barcelona: Grijalbo. 
